\title{
A calcium blocking and anticholinergic agent (terodiline) in the treatment of detrusor hyperreflexia: a placebo-controlled, cross-over trial
}

\author{
THOR PETERSEN, JOHANNES JAKOBSEN \\ From the Department of Neurology, University Hospital of Aarhus, Denmark
}

SUMMARY In 25 neurological patients with detrusor hyperreflexia terodiline reduced the number of total micturitions during daytime. Bladder capacity was increased and amplitude of the bladder contractions was reduced. An increase in residual urine was also observed. Mild anticholinergic side-effects were measured on pupillary motility and on heart rate variation. It is concluded that terodiline is a useful alternative in treatment of patients with detrusor hyperreflexia.

Pharmacological treatment of urinary frequency and incontinence due to detrusor hyperreflexia by anticholinergic agents is often unsuccessful. Blockade of parasympathetic activity may be insufficient and, furthermore, systemic anticholinergic effects often give rise to complaints and withdrawal of therapy. ${ }^{1-4}$ Consequently, there is a need for a new pharmacological approach to the treatment of bladder hyperreflexia. Calcium blocking agents with smooth muscle relaxing properties might well be such an alternative. Recently compounds have been developed that combine an anticholinergic effect with calcium blockade. This combination could possibly improve bladder function in patients with detrusor hyperreflexia without giving rise to more systemic anticholinergic side-effects. Terodiline has shown this combined anticholinergic and calcium blocking effect in in vitro studies of muscle strip preparations ${ }^{5}$ and a therapeutic clinical effect has been obtained in patients with idiopathic detrusor instability. ${ }^{6}$ In clinical studies it has proved to be safe with only mild anticholinergic side-effects ${ }^{7}$ and systemic bioavailability of the drug is high. ${ }^{8}$

We have conducted a randomised, placebocontrolled, double-blind, cross-over study of the effect of terodiline on bladder function in patients with detrusor hyperreflexia. Also the effect on cholinergic functions, that is, pupil motility and heart rate, as well as a possible therapeutic effect on lower limb spasticity have been evaluated.

Address for reprint requests: Thor Petersen, MD, Neurological Laboratory, Department of Neurology, Aarhus Kommunehospital, 8000 Aarhus C, Denmark.

Received 16 December 1986. Accepted 24 February 1987

\section{Materials and methods}

Patients with neurological diseases, urinary frequency and/or incontinence and with detrusor hyperreflexia, as defined by the International Continence Society, ${ }^{9}$ were eligible for study. Frequency was defined as eight or more passages of urine per day. Overall disability score was rated according to a previous report ${ }^{10}$ and recorded together with body weight and blood pressure before entrance to the study and at follow-up examinations. The study was approved by the Ethical Committee and informed consent was obtained from the patients before start of the study.

Exclusions Patients with urinary tract infection and patients with suspected prostatic enlargement, as evaluated from the urethral pressure profile and from the maximal urinary flow, were excluded. Patients with glaucoma, severe urinary retention, decreased liver and kidney function, and pregnant patients were also excluded.

Design of study After 1 week without any medication for bladder dysfunction the patients were allocated at random to terodiline $25 \mathrm{mg}$ or identical placebo tablets twice daily for 4 weeks. Cross-over took place after a drug free runout period of 1 week. To avoid urinary bladder infections during the trial antibiotics were given throughout the whole investigation period.

Urodynamic studies Patients were asked for preference of treatment period. To register voiding frequency and incontinence episodes they filled in a micturition chart during the last week of each treatment period. Before entrance to the study cystometry and pressure voiding were performed and at the end of the two treatment periods the cystometry was repeated, together with measurement of the residual urine. Water cystometry was carried out with a balloon catheter transurethrally and with physiological saline as filling medium at an infusion rate of $15 \mathrm{ml} / \mathrm{min}$. Urinary flow was measured by a mictiometer (DISA, Copenhagen). The following parameters were recorded: Bladder volume at first contraction, mean pressure amplitude of the first three bladder contractions and bladder capacity defined as the volume 
when uninhibited contractions occurred for more than 10 minutes or when the resting pressure exceeded $1 \mathrm{kPa}$. For further details refer to reference 9.

Studies of anticholinergic side-effects Patients were asked about the occurrence of dry mouth, blurred vision and urinary retention, whereas other side-effects were reported spontaneously. For quantitative determination of anticholinergic side-effects pupil motility was measured by pupillography and heart rate variation by electrocardiography in the first 10 consecutive patients included in the study.

During pupillography continuous measurements of the area of the left pupil were performed with an infrared sensitive TV-camera (Iriscorder, Hamamatsu TV Corporation, Japan). ${ }^{11}$ For determination of pupil area at various levels of illumination and of the pupillary light response a converging beam of yellow-green light, reaching the eye with a diameter of $1 \mathrm{~mm}$ in the plane of the pupil, and the retina one papillary diameter above the optic disc was applied. The light reflex was elicited by a square wave stimulus for $256 \mathrm{~ms}$ with a light intensity of $512 \mu \mathrm{Lm}$. The following response parameters were evaluated: the stimulus threshold, the latency, the relative amplitude and dilatation time until half of the contraction amplitude was regained.

Cardiovascular reflexes were studied as heart rate variation (HRV) during various conditions by simple bedside tests. ${ }^{12}$ At rest in a supine position 150 consecutive $R-R$ intervals were recorded with no attention being paid to breathing. Heart rate variation was expressed as the standard deviation of the mean consecutive difference of $\mathbf{R}-\mathbf{R}$ intervals $\left(\mathrm{SD}_{\mathrm{MCD}}\right)$, which reflects rapid shifts in beat-to-beat variation and as the standard deviation of all $R-R$ intervals $\left(S_{R-R}\right)$, a measure of longer lasting shifts in heart rate. ${ }^{12}$ The heart rate response to deep breathing was registered for $90 \mathrm{~s}$ at rates of $3,4,5,7.5$ and 10 breaths per minute, the HRV being expressed as the SD of all R-R intervals during each breathing period. The heart rate response to standing was recorded for 60 seconds and was expressed as the ratio between the 30th and the 15th heart beat. ${ }^{12}$

Studies of spasticity in the legs Detrusor hyperreflexia occasionally provokes flexor spasms in the lower limbs. ${ }^{13}$ This spasticity is inversely related to the voluntary muscle strength. ${ }^{14}$ We therefore measured isokinetic power of knee extension in patients with sufficient strength and in patients with flexor spasms. These spasms were counted during one night by special equipment described previously. ${ }^{15}$

Compliance At the end of each treatment period tablets were counted and blood samples taken for determination of serum terodiline level. One patient refused blood sampling. Statistics Effects and side-effects of terodiline treatment
Table 1 Clinical data of the 11 men and 14 women (18 had multiple sclerosis, one syringomyelia, one cervical medullopathy, one hereditary encephalopathy, two cerebral atrophy, one sequela from cerebral trauma and one from meningitis)

\begin{tabular}{lc}
\hline & Mean and ranges \\
\hline Disability score & $12(2-24)$ \\
Age & $45(29-64)$ years \\
Weight & $66(37-93) \mathrm{kg}$ \\
Duration of symptoms & $6(1-20)$ years \\
\hline
\end{tabular}

were expressed as the difference between the values obtained in the periods of treatment with the active component and the placebo preparation. Differences were analysed statistically by the paired $t$ test using a $5 \%$ limit of significance. Test for a period effect and carry-over effect was performed in accordance with a previous report. ${ }^{16}$

\section{Results}

All of the included 25 patients completed the study. Their clinical data are shown in table 1. During the run-in period the number of voluntary micturitions was $8.2(\mathrm{SD}=4 \cdot 7)$ and involuntary micturitions 3.4 $(\mathrm{SD}=4 \cdot 1)$. Overall disability score, blood pressure and body weight were unchanged during the study. In all but one patient terodiline was present in the serum at levels varying between 120 and $2160 \mu \mathrm{g}$ per litre (mean $625 \mu \mathrm{g} / \mathrm{l}$ ). The one patient with undetectable serum concentration had stopped medication 2 days prior to the end of the scheduled treatment. She had an empty pill glass and, therefore, was not excluded from study.

Patients evaluation Eight patients preferred the active drug, five preferred the placebo and five other patients liked both preparations equally well. Four patients preferred none of the treatment periods to the run-in phase and the last three patients reported deterioration of voiding symptoms during the active drug treatment period because of decreased bladder emptying. In these three patients detrusor-sphincter dyssynergia was observed. The number of voluntary and involuntary micturitions during the two treatment periods are shown in table 2. A slight but

Table 2 Voluntary and involuntary micturitions per day in 25 patients with detrusor hyperreflexia after four weeks of treatment with placebo and terodiline

\begin{tabular}{llll}
\hline & $\begin{array}{l}\text { Placebo } \\
(\text { mean } \pm S D)\end{array}$ & $\begin{array}{l}\text { Terodiline } \\
\text { (mean } \pm S D)\end{array}$ & $\begin{array}{l}\text { Paired difference } \\
\text { (mean } \pm S D)\end{array}$ \\
\hline Voluntary micturitions & $6.8 \pm 3.9$ & $6.4 \pm 2.8$ & $0.4 \pm 1.9$ \\
Involuntary micturitions & $2 \cdot 6 \pm 4 \cdot 0$ & $2.1 \pm 3.3$ & $0.5 \pm 1.9$ \\
Total during daytime & $8 \cdot 5 \pm 3 \cdot 1$ & $7.6 \pm 2.6$ & $0.9 \pm 2.0^{*}$ \\
Total during night-time & $0.9 \pm 0.6$ & $0.9 \pm 0.7$ & $0.0 \pm 0.5$ \\
\hline
\end{tabular}

$*$ indicates $p<0.05$. 
Table 3 Cystometric findings in 25 patients with detrusor hyperreflexia after four weeks of treatment with placebo and terodiline

\begin{tabular}{|c|c|c|c|c|}
\hline & $N$ & $\begin{array}{l}\text { Placebo } \\
(\text { mean } \pm S D)\end{array}$ & $\begin{array}{l}\text { Terodiline } \\
(\text { mean } \pm S D)\end{array}$ & $\begin{array}{l}\text { Paired difference } \\
(\text { mean } \pm S D)\end{array}$ \\
\hline $\begin{array}{l}\text { Volume at } 1 \text { contraction } \\
\text { Amplitude of contraction } \\
\text { Bladder capacity } \\
\text { Residual urine }\end{array}$ & $\begin{array}{l}21 \\
21 \\
25 \\
25\end{array}$ & $\begin{array}{l}151 \pm 122 \\
9 \cdot 2 \pm 4 \cdot 3 \\
413 \pm 191 \\
118 \pm 77\end{array}$ & $\begin{array}{l}191 \pm 145 \\
7 \cdot 2 \pm 3 \cdot 3 \\
480 \pm 200 \\
179 \pm 120\end{array}$ & $\begin{array}{l}40 \pm 65 \mathrm{ml}^{*} \\
1.9 \pm 2.9 \mathrm{kPa}^{\dagger} \\
67 \pm 121 \mathrm{ml}^{*} \\
61 \pm 94 \mathrm{ml}^{\dagger}\end{array}$ \\
\hline
\end{tabular}

${ }^{*} \mathrm{p}<0.02$ and $\mathrm{pp}<0.01$.

significant improvement in total number of micturitions during daytime was obtained during treatment with terodiline. Voluntary micturitions were significantly reduced from the first to the second period but no carry-over effect was observed in any parameter.

Urinary bladder function Detrusor-sphincter dyssynergia was observed in four patients during pressure voiding, one of whom had been treated with intermittent self-catheterisation for many years. In four patients volume at first bladder contraction could not be evaluated, because the detrusor hyperreflexia disappeared during the study. Cystometric findings are shown in table 3 and individual values in figs 1 and 2 . Treatment with terodiline resulted in a significant suppression of the detrusor hyperreflexia, that is, increased volume at first bladder contraction and decreased amplitudes of contractions as well as an increased bladder capacity. However, terodiline also led to an increase in the residual urine. No relation between these changes and the subjective improvement or the serum levels of terodiline was obtained.
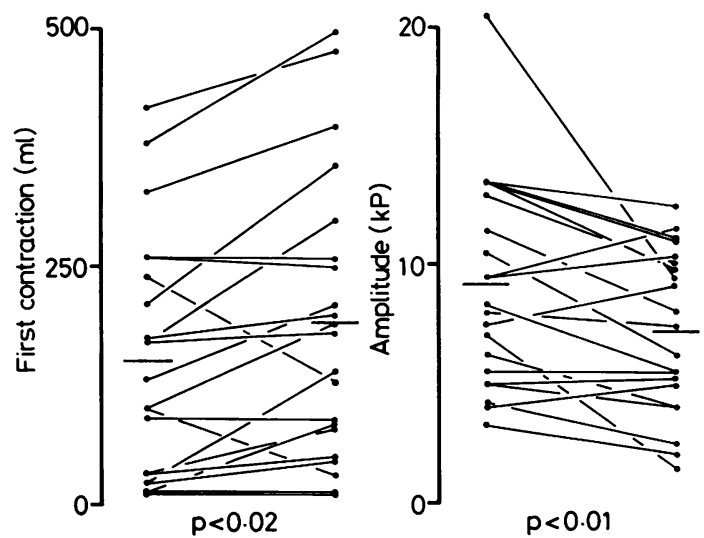

Fig 1 Paired observations of bladder volume at first detrusor contraction during cystometry and the amplitude of the contractions in 21 patients treated with placebo (left) and terodiline (right).
Side-effects Subjective side-effects are shown in table 4 . In addition three patients reported nausea and two complained of weight gain during the period of active drug treatment and one during the placebo period. The pupil area at various light intensities as well as the parameters of the pupillary light response are given in table 5. Treatment with terodiline increased pupil area in absolute darkness, following constant illumination at $1 \mu \mathrm{Lm}$ and $512 \mu \mathrm{Lm}$ and at increasing light intensity of $8 \mu \mathrm{Lm} / \mathrm{s}$. There was a tendency for an overall impairment of the cholinergic response of the light reflex with increase of stimulus threshold, prolongation of the latency and diminution of the amplitude and the redilatation time. Individual values of the latency and the amplitude of the pupillary light reflex are shown in fig 3 . Table 6 gives $\mathrm{HRV}$ at rest and in response to standing. Terodiline treatment led to reduced pulse rate but did not influence HRV either at rest or in the erect position. However, HRV at deep breathing at various respiratory rates was diminished at 4,5 and 7.5 respiratory cycles per minute, as shown in fig 4.

Spasticity in the legs No changes in the isokinetic

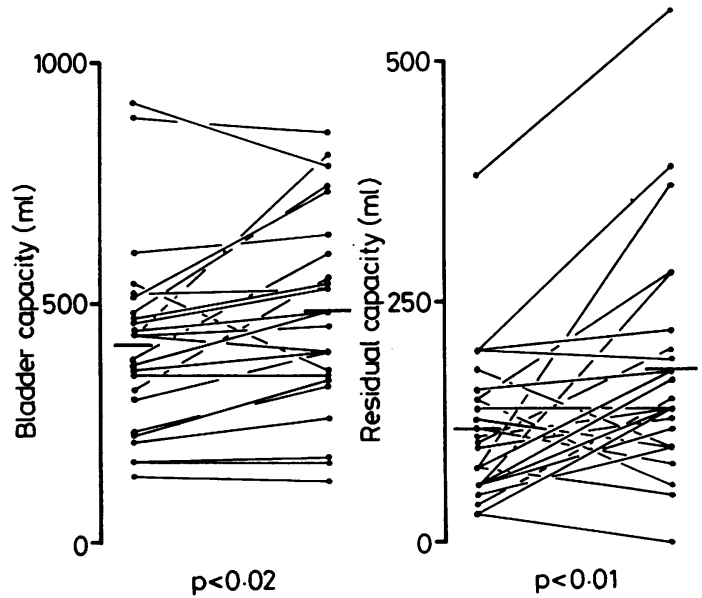

Fig 2 Paired observations of maximum urinary bladder capacity and residual urine in 25 patients treated with placebo (left) and terodiline (right). 
Table 4 Number of patients with detrusor hyperreflexia, who reported side-effects after four weeks of treatment with placebo and terodiline

\begin{tabular}{llr}
\hline & Placebo & Terodiline \\
\hline Dry mouth & $5(20 \%)$ & $12(48 \%)$ \\
Blurred vision & 0 & $7(28 \%)$ \\
Urinary retention & 0 & $6(24 \%)$ \\
\hline
\end{tabular}

power of the lower limbs were registered in the 12 patients studied. The number of flexor spasms were counted in five patients. No changes were registered in four cases, but in one patient, elimination of detrusor hyperreflexia was followed by a $75 \%$ reduction of the number of flexor spasms.

\section{Discussion}

The present placebo controlled, clinical trial in patients with urinary bladder hyperreflexia has shown that treatment with the anticholinergic and calcium blocking agent, terodiline, reduces frequency of micturition and detrusor hyperreflexia and improves bladder capacity. The response of terodiline treatment observed in these patients with severe voiding disturbances seems similar to the response obtained in previous controlled studies of pure anticholinergic drugs. $^{1-417}$ The clinical efficacy in the present study was less pronounced compared with the efficacy in patients studied with idiopathic detrusor instability ${ }^{67}$ However, in contrast to these studies we observed an increased residual urine in connection to depression of the detrusor hyperreflexia, as described previously. ${ }^{3417}$ Individual dosage and concomitant treatment in case of decreased bladder emptying are therefore important in neurological patients and are likely to produce even better effects. In contrast to what has been reported from studies on pure anticholinergic agents ${ }^{17}$ we observed a significant reduction in the amplitude of bladder contractions. This finding can be explained by the calcium blocking effect of terodiline since this effect primarily impairs smooth muscle contractility. ${ }^{5}$ Despite the combined calcium blocking and anticholinergic effect some of the patients studied showed unchanged voiding symptoms and unchanged bladder function at cystometry, even in cases of high serum levels of terodiline. This could possibly be due to inaccessible receptors at the cholinergic neuromuscular junctions ${ }^{18}$ or to the involvement of other neurotransmitters in bladder hyperreflexia. Various transmitters could play such a role such as prostaglandins, vasoactive intestinal polypeptides or purinergic innervation or yet unidentified substances. ${ }^{19} 20$

In the present study we also observed a beneficial effect on the number of micturitions from the first to

Table 5 Pupil area at various light intensities as well as parameters of the pupillary light response in the first 10 patients with detrusor hyperreflexia after treatment with placebo and terodiline

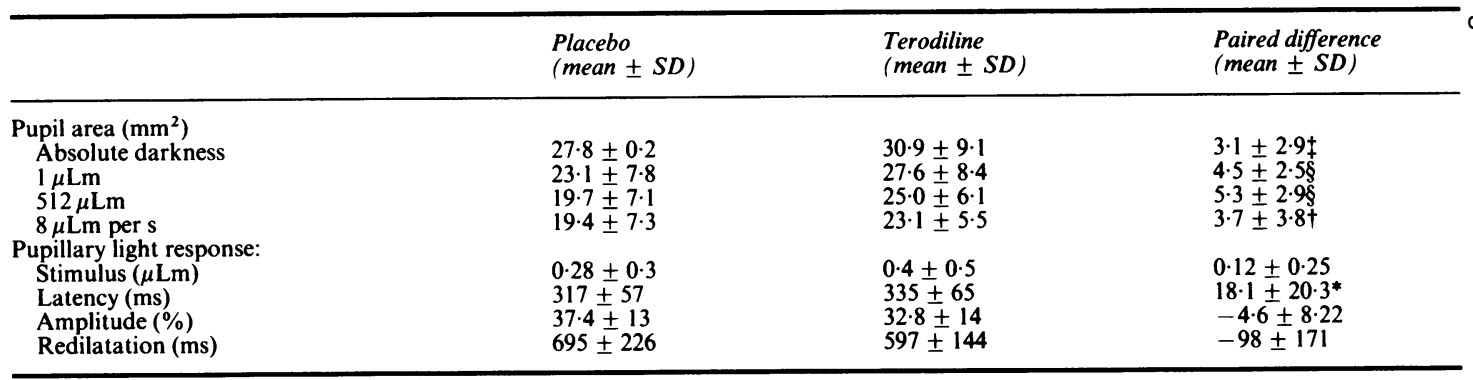

${ }^{*} \mathrm{p}<0.05,+\mathrm{p}<0.02, \ddagger \mathrm{p}<0.01, \S \mathrm{p}<0.001$.

Table 6 Pulse interval and heart rate variation at rest and heart rate response to standing in the first 10 patients with detrusor hyperreflexia after treatment with placebo and terodiline

\begin{tabular}{|c|c|c|c|}
\hline & $\begin{array}{l}\text { Placebo } \\
(\text { mean } \pm S D)\end{array}$ & $\begin{array}{l}\text { Terodiline } \\
(\text { mean } \pm S D)\end{array}$ & $\begin{array}{l}\text { Paired difference } \\
(\text { mean } \pm S D)\end{array}$ \\
\hline $\begin{array}{l}\text { At rest (ms): } \\
\text { Pulse interval } \\
\text { SD } D_{R-R} \\
\text { SD } \\
\text { MCD }\end{array}$ & $\begin{array}{l}832 \pm 111 \\
28.5 \pm 8.7 \\
17.9 \pm 7.5\end{array}$ & $\begin{array}{l}885 \pm 105 \\
30 \cdot 6 \pm 7 \cdot 5 \\
18 \cdot 5 \pm 11 \cdot 3\end{array}$ & $\begin{array}{l}53 \pm 54^{*} \\
2.2 \pm 10.4 \\
0.7 \pm 10.4\end{array}$ \\
\hline $\begin{array}{l}\text { Standing: } \\
30: 15 \text { ratio }\end{array}$ & $1 \cdot 26 \pm 0.21$ & $1 \cdot 22 \pm 0.26$ & $-0.04 \pm 0.19$ \\
\hline
\end{tabular}

${ }^{*} \mathrm{p}<0.02$. 
Pupillary light reflex
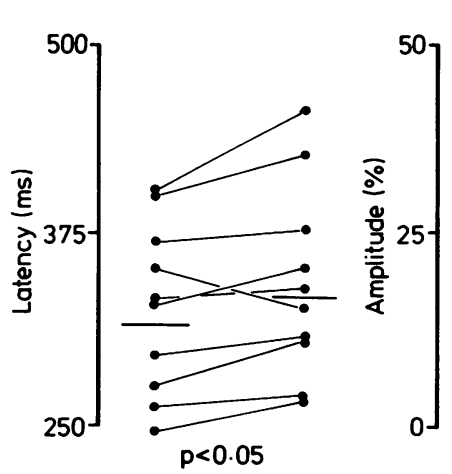

caused by bladder training as described in a previous study. ${ }^{21}$

The therapeutical efficacy in relation to the occurrence of side-effects (the therapeutical ratio) was high during terodiline treatment. We measured cholinergic functions of pupil motility and heart rate variation and found only mild anticholinergic effects after treatment with terodiline. ${ }^{22}{ }^{23}$ Side-effects were reported by nearly half of the patients, but none of them discontinued the medication. Since gain of body weight only was found in a few of our patients the suspected vasodilatory effect of terodiline is presumably small. This is supported also by the lack of reflex tachycardia. In fact we found a decrease in heart rate, most likely mediated by a calcium blockade of the sinus node. ${ }^{24}$

Thus the degree of systemic anticholinergic side-

Fig 3 Paired observations of the latency and the amplitude of the pupillary light response in 10 patients treated with placebo (left) and terodiline (right).

the second period of treatment independently of whether terodiline or placebo was given and an even more pronounced decrease of micturitions when compared to run-in values. This effect probably was

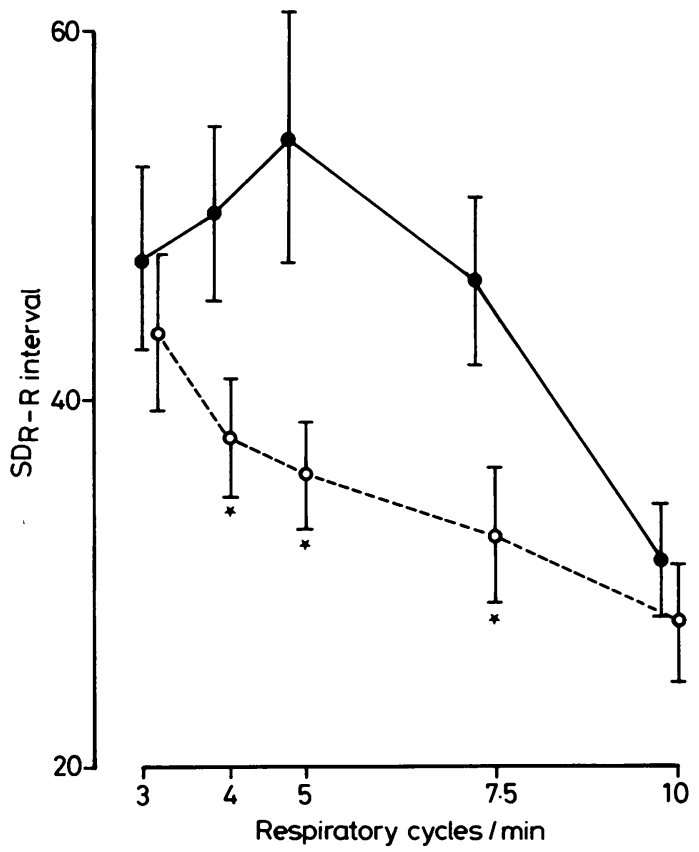

Fig 4 Respiratory heart rate variation at deep breathing at $3,4,5,7 \cdot 5$ and 10 respiratory cycles per minute in 10 patients treated with placebo and terodiline (open circles). Terodiline obliterates the characteristic cholinergic maximum response at 5 respiratory cycles per minute. Values are means \pm SEM. effects seems less pronounced compared with traditional anticholinergic therapy. ${ }^{1-417}$ However, urinary retention, especially in patients with detrusorsphincter dyssynergia, occurred as described after treatment with pure anticholinergic agents and management with for instance intermittent clean catheterisation should be instituted when indicated.

The study was supported by the Danish Multiple Sclerosis Society. We thank Mrs Lis Oades for linguistic advice.

\section{References}

1 Hebjørn S. Treatment of detrusor hyperreflexia in multiple sclerosis. Urol Int 1977;32:209-17.

2 Gajewsky JB, Awad SA. Oxybutynin versus propantheline in patients with multiple sclerosis and detrusor hyperreflexia. J Urol 1986;136:966-8.

3 Blaivas JG, Labib KB, Michalik SJ, Zayed AAH. Cystometric response to propantheline in detrusor hyperreflexia: therapeutic implications. J Urol 1980;124:259-62.

4 Pedersen E, Grynderup V. Effect of hydramitrazine (Lisidonil) in the treatment of neurogenic bladder dysfunction. $\mathrm{Br}$ Med $J$ 1966;2:271-3.

5 Husted S, Andersson K-E, Sommer L, Østergaard JR. Anticholinergic and calcium antagonistic effects of terodiline in rabbit urinary bladder. Acta Pharmacol Toxicol 1980;46, Suppl I: $20-30$.

6 Ulmsten U, Ekman G, Andersson K-E. The effect of terodiline treatment in women with motor urge incontinence. $\mathrm{Am} \mathrm{J}$ Obstet Gynecol 1985;153:169-22.

7 Peters D. The Multicentre Study Group. Terodiline in the treatment of urinary frequency and motor urge incontinence. A controlled multcentre trial. Scand J Urol Nephrol 1984;Suppl 87:21-35.

8 Andersson K-E. Clinical pharmacology of terodiline. Scand J Urol Nephrol 1984;Suppl 87:13-20.

9 Petersen T, Pedersen E. Neurourodynamic evaluation of voiding dysfunction in multiple sclerosis. Acta Neurol Scand 1984; 69:402-11.

10 Grynderup V. A comparison of some rating systems in multiple sclerosis. Acta Neurol Scand 1969;45:611-22.

11 Gundersen HJG. A new photostimulator and videopupillograph 
for quantitative neuroophtalmological studies. Ophtalmologica 1976;172:62-8.

12 Ewing DJ. Practical bedside investigation of diabetic autonomic failure. In: Bannister R, ed. Autonomic Failure. A Textbook of Clinical Disorders of the Autonomic Nervous System. Oxford: Oxford University Press, 1983:371-405.

13 Pedersen E, Petersen T, Schrøder HD. Relation between flexor spasms, uninhibited detrusor contractions and anal sphincter activity. J Neurol Neurosurg Psychiatry 1986;49:273-7.

14 Knutsson E, Mårtensson A. Dynamic motor capacity in spastic paresis and its relation to prime mover dysfunction, spastic reflexes and antagonist co-activation. Scand J Rehab Med 1980;12:93-106.

15 Pedersen E, Klemar B, Tørring J. Counting of flexor spams. Acta Neurol Scand 1979;60:164-9.

16 Hills M, Armitage P. The two-period cross-over clinical trial Br J Clin Pharmacol 1979;8:7-20.

17 Pedersen E. Studies of the effect and mode of action of flavoxate in human urinary bladder and sphincter. Urol Int 1977;32: 202-8.
18 Elmer M. Cholinergic mechanisms in the rat detrusor muscle. Acta Pharmacol Toxicol 1978;43(II):63-8.

19 Burnstock G, Cocks T, Crowe R, Kasakov L. Purinergic innervation of the guinea-pig urinary bladder. $\mathrm{Br} J$ Pharmacol 1978;63:125-38.

20 Kinder RB, Restorick JM, Mundy AR. Vasoactive intestinal polypeptide in the hyperreflexic neuropathic bladder. Br J Urol 1985;57:289-91.

21 Klarskov P, Gerstenberg TC, Hald T. Bladder training and terodiline in females with idiopathic urge incontinence and stable detrusor function. Scand J Urol Nephrol 1986;20:41-6.

22 Jakobsen J, Hauksson P, Vestergaard P. Heart rate variation in patients treated with antidepressants. An index of anticholinergic effects. Psychopharmacology 1984;84:544-9.

23 Lowenstein O, Lowenstein IE. Mutual role of sympathetic and parasympathetic in shaping of the pupillary reflex to light. Pupillographic studies. Arch Neurol Psychiatry 1950;64: $341-77$.

24 Snyder SH, Reynolds IJ. Calcium-antagonist drugs. $N$ Engl J Med 1985;313:995-1002. 